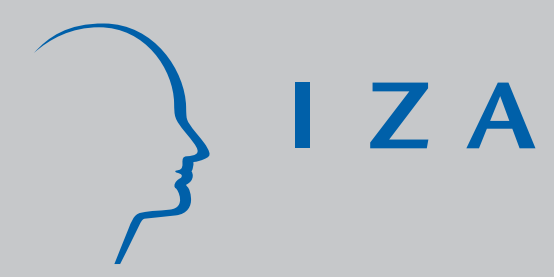

IZA DP No. 3274

A Public Good Version of the Collective Household Model: An Empirical Approach with an Application to British Household Data

Chris van Klaveren

Bernard van Praag

Henriette Maassen van den Brink

J anuary 2008 


\title{
A Public Good Version of the Collective Household Model: An Empirical Approach with an Application to British Household Data
}

\author{
Chris van Klaveren \\ SCHOLAR, University of Amsterdam \\ Bernard van Praag \\ SCHOLAR, University of Amsterdam \\ and IZA \\ Henriette Maassen van den Brink \\ SCHOLAR, University of Amsterdam
}

Discussion Paper No. 3274

January 2008

IZA

P.O. Box 7240

53072 Bonn

Germany

Phone: +49-228-3894-0

Fax: +49-228-3894-180

E-mail: iza@iza.org

\begin{abstract}
Any opinions expressed here are those of the author(s) and not those of IZA. Research published in this series may include views on policy, but the institute itself takes no institutional policy positions.

The Institute for the Study of Labor (IZA) in Bonn is a local and virtual international research center and a place of communication between science, politics and business. IZA is an independent nonprofit organization supported by Deutsche Post World Net. The center is associated with the University of Bonn and offers a stimulating research environment through its international network, workshops and conferences, data service, project support, research visits and doctoral program. IZA engages in (i) original and internationally competitive research in all fields of labor economics, (ii) development of policy concepts, and (iii) dissemination of research results and concepts to the interested public.
\end{abstract}

IZA Discussion Papers often represent preliminary work and are circulated to encourage discussion. Citation of such a paper should account for its provisional character. A revised version may be available directly from the author. 


\begin{abstract}

\section{A Public Good Version of the Collective Household Model: An Empirical Approach with an Application to British Household Data*}

In this paper we consider an empirical collective household model of time allocation for twoearner households. The novelty of this paper is that we estimate a version of the collective household model, where the internally produced goods and the externally purchased goods are assumed to be public. The empirical results suggest that: (1) Preferences of men and women differ; (2) Although there are significant individual variations, on average the utility functions of men and women are equally weighted in the household utility function; (3) Differences in the ratio of the partners' hourly wages are explanatory for how individual utilities are weighted in the household utility function. (4) The female's preference for household production is influenced by family size, but this does not hold for the male; (5) Both the male and the female have a backward-bending labor supply curve; (6) Labor-supply curves are forward-bending with respect to the partner's wage rate; (7) Our model rejects the unitary Slutsky symmetry condition.
\end{abstract}

JEL Classification: D12, D13, J22

Keywords: collective household models, household behavior, labor supply, intra-household, time allocation

Corresponding author:

Chris van Klaveren

Department of Economics and Econometrics

University of Amsterdam

Roetersstraat 11

1018 WB Amsterdam

The Netherlands

E-mail: c.p.b.j.vanklaveren@uva.nl

\footnotetext{
* We are grateful to Pierre-André Chiappori and Frederic Vermeulen for their constructive and encouraging remarks.
} 


\section{Introduction}

It is now recognized that, if a male and a female are living together, in almost all cases the partners will not act in splendid isolation. Their way of spending money and of spending their time, both within the household and on the labor market, will be interdependent. Hence, a separate analysis of male and female labor supply may be deceptive when we ignore this potential interdependency.

The obvious setting in which to study this joint labor supply vector is a non-unitary model. The essential innovation of this non-unitary view is the recognition that the husband and the spouse in a household are separate individuals with their specific preferences. ${ }^{1}$ In this paper we use a collective model of household behavior. Following the collective view, spouses are living together, so to speak, in a Pareto-equilibrium. This is an equilibrium situation, both with respect to the level of what is bought and consumed and with respect to the level of hours supplied by the two household members to the labor market and to household production .

The labor choice of the female affects not only the consumption and utility level of the female but also that of the husband. The household income is a kind of public good $(Y)$ within the household ${ }^{2}$. This does not imply that out of the household income no commodities are bought that can only be consumed by one of the two spouses, e.g. clothing, the barber, etc., but it does imply that even then a purchase by one of them needs the explicit or implicit approval of the other partner. It is an issue of the power distribution between the two partners who in the end gets most of the pie. Actually, we may discern two sides of the coin with respect to the male's (and the female's) outside labor supply. His direct labor effort (or enjoyment) is his own, but the ensuing money outcome of his labor is shared with his partner and hence also affects the partner's utility function through the household income.

The second public good in the household is what we call the level of household care

\footnotetext{
${ }^{1}$ See, among others: Grossbard (1976), Grossbard-Shechtman (1984), Kooreman \& Kapteyn (1987), McElroy (1990), Carlin (1990), McElroy (1990), Duguet \& Simonnet (2007).

${ }^{2}$ See also Browning, Chiappori \& Lechene (2006), who show that income pooling is neither necessary nor sufficient to describe a household as a unitary household.
} 
$(H)$, defined as the sum of hours spent by both partners on what they call 'household tasks'. These tasks include cooking, cleaning, doing the laundry and other such activities. Of course, the distinction between housework and leisure may be ambiguous, and therefore we leave the empirical definition to the respondents themselves. Some love cooking and see it as a leisure activity; others hate cooking and see it as housework. Here again the direct effort (or enjoyment) linked to housework is for the individual who spends his time on it, but the ensuing product is a public good $H$, and hence also affects the partner's utility function through $H$.

In household economics it is generally assumed that households face two interconnected decision problems. The first problem is how to divide the hours of male and female over the different time- consuming categories. The second problem is how to divide the income earned among various consumption categories. In this paper we explain the 'time spending' problem, while we leave the consumer spending problem aside, since we do not have the relevant information in our data set (see Browning \& Gørtz, 2005, where time and money spending is studied simultaneously).

In recent years different theoretical models have been developed that describe how households solve the 'time using' problem. The first and oldest approach is the unitary model developed by Mincer (1963), Becker $(1965,1991)$ and Lancaster (1966). The unitary model equates households with a single (selfish) individual, even though these households may be multi-person households. The restriction imposed on household behavior by the unitary model is that the Slutsky matrix must be symmetric. This condition implies that the marginal compensated wage changes of the two partners must have the same effect on each other's labor supply. This assumption seems unrealistic and therefore we cannot apply the unitary model. We explicitly start from the notion that it is important who in the household generates income, and that wage changes of the two partners may have different effects on each other's labor supply (see also Browning et al., 2006).

Currently, there are many empirical papers that reject the assumptions of the unitary model: see, among others Thomas (1990), Browning, F, Bourguignon, Chiappori \& Lechene 
(1994), Lundberg, Pollak \& Wales (1997), Fortin \& Lacroix (1997), Browning \& Chiappori (1998), Blundell, Chiappori, Magnac \& Meghir (2007). Excellent recent surveys are given by Vermeulen (2002), Browning et al. (2006) and Donni (2008).

In the 1980s Chiappori $(1988,1992,1997)$ and Apps \& Rees (1988) introduced the collective model $(C M)$ of household behavior. The $C M$ approach starts from the minimal assumption that the outcome of the household decision process should be a Pareto-efficient outcome. As compared with the unitary model this model does not impose Slutsky symmetry or income pooling.

The early empirical approaches focused mainly on the development of theory and on testing and refuting the unitary model. Over the last 20 years, more and more empirical approaches are using the collective setting as the basic framework. ${ }^{3}$ However, less attention is given to the allocation of time where domestic work is taken into account. Exceptions are Apps \& Rees (1997), Apps \& Rees (1999), Rapoport, Sofer \& Solaz (2005) and Couprie (2007).

In the present paper we develop a structural collective household model of time allocation, assuming that internally produced household services and externally purchased market goods are public goods in the household, while the direct time expenditures by each partner (paid work, housework and leisure) affect only the utility of the individual time spender. A public good is usually understood to be a good where the consumption by one person does not exclude the consumption of the same good by another person. Here we stretch the concept somewhat as, for instance, the consumption of going to the barber, although financed out of the common purse, can only be for one partner. In the present situation the public good is characterized by the fact that personal 'inputs' do not automatically equal personal 'outputs'. For instance, when considering the traditional household model where only the male earns labor income, then part of that money is spent by the female in favor of herself. Similarly, the housework performed by the female is also enjoyed by the male.

In the Pareto-equilibrium of the collective (non-unitary) model, the equilibrium may be

\footnotetext{
${ }^{3}$ See, among others , Fortin \& Lacroix (1997), Chiappori, Fortin \& Lacroix (2002), Blundell, Chiappori, Magnac \& Meghir (2007), Browning \& Gørtz (2005), Donni (2008) and Donni and Moreau (2007).
} 
described as the result of optimizing the household utility function, which is defined as a weighted sum of the male's and the female's utility function. The weights are generally referred to as Pareto-weights. A crucial and necessary assumption in the $C M$ is that the Pareto-weights depend on exogenous variable(s) like the wage rates of both household members, because otherwise the model would coincide with the unitary model.

The empirical model that we are to estimate in this paper is similar to the theoretical model described in a recent paper by Chiappori \& Ekeland (2006). There they derive theoretically when collective household models are non-parametrically identifiable. One of the specific identifiable cases they refer to is a model where at least one consumption good of each household member is an exclusive good. In our model we consider each spouse's leisure as an exclusive good and assume that consumption goods are public. ${ }^{4}$

We propose an iterative estimation method, by which it is possible to estimate (ordinal) utility functions of both the male and the female and to estimate the Pareto-weight as a function of individual wages. In addition the wage-, child- and non-labor-income effects on time-spending behavior are obtained for both partners. For this purpose we use data from the British Household Panel Survey (BHPS).

We note that the model is estimated on a restricted data set of households where both partners have a paid job, and this may induce a selectivity bias. However, formulating a collective model where we also consider corner solutions is beyond the scope of this paper.

The structure of this paper is a follows. In Section 2 we develop the collective model to be estimated. In Section 3 the estimation method is explained. In Section 4 we describe the data that are used and we present the estimation results. In Section 5 we discuss the policy-relevant wage-, child- and non-labor-income effects in terms of elasticities and crosselasticities between partners. Section 6 concludes.

\footnotetext{
${ }^{4}$ We notice that in Chiappori $(1988,1992)$ consumption goods are assumed to be purely private, while in our paper they are considered as public goods.
} 


\section{The Model}

Before introducing the collective model it is useful to make a digression to the literature of individual labor supply. In the theory of individual labor supply the individual utility function is $U=U(q, t)$, where $q$ stands for a consumption bundle of market goods and $t$ for a vector of time expenditures, say $\left(t_{1}, t_{2}, t_{3}\right)$, denoting leisure, housework and job hours, respectively. Utility is maximized under the budget constraint $w \cdot t_{3}=p^{\prime} q$ and the time budget constraint $t_{1}+t_{2}+t_{3}=T$, where $w$ stands for hourly wage. If we have no information about consumption $q$, we assume a Hicksian composite commodity, the value of which is income $y\left(=w \cdot t_{3}\right)$. Then we may write the utility function as $U=U\left(y\left(t_{3}\right), t_{1}, t_{2}, t_{3}\right)$. We note that this is not an indirect utility function, since here $y$ stands for a composite commodity. This somewhat unusual expression demonstrates that spending time $t_{3}$ on paid work has two effects on utility. The first is positive as working generates income, i.e. consumption. The second effect is mostly assumed to be negative as the working effort is thought to reduce utility. ${ }^{5}$ In a similar way we might split the household effort $t_{2}$ into two effects: a positive effect with respect to the level of household care $H=H\left(t_{2}\right)$, where $H\left(t_{2}\right)$ stands for the household production function, and a negative effect because most people do not like the effort identified with housework $t_{2}{ }^{6}$ Including $H$ we may write in a similar way $U=U(y, H, t)=U\left(y\left(t_{3}\right), H\left(t_{2}\right), t_{1}, t_{2}, t_{3}\right)$, where both $t_{2}$ and $t_{3}$ figure twice, once in their 'input'-role, and once in their 'output'-role. Obviously, these formulations look a bit like hair-splitting in the individual case. However, in the collective case this distinction makes sense as the input effort may fall on one partner while both partners or even, exclusively, the other partner, may enjoy the output.

More precisely, we may write the utility function of household member $i$ as: ${ }^{7}$

$$
U_{i}=U_{i}\left(Y\left(t_{3 m}, t_{3 f}\right), H\left(t_{2 m}, t_{2 f}\right), t_{1 i}, t_{2 i}, t_{3 i}\right) ; \quad i=(m, f)
$$

\footnotetext{
${ }^{5}$ It may be, as many psychologists and sociologists claim, that participation as such is welfare increasing. Then we have two positive effects.

${ }^{6}$ Note that some men and women like household work as a way of self-realization, that is, it is utility increasing. In that case, the effort effect would be positive.

${ }^{7}$ For a similar argument see also Grossbard, 2005: 217)
} 
Let us now rename our variables in a more familiar way. We assume that both partners $i$ $(=m, f)$ have a log-additive utility function in the individual variables leisure $l e_{i}$, housework hours $w h_{i}$, job hours $j h_{i}\left(=T-l e_{i}-w h_{i}\right)$, and the public goods: household income $(Y)$ and household care level $(H)$. We specify the household production function as the productivity weighted sum of the hours that both partners spend on household activities, i.e. $H=$ $\left(w h_{m}+\gamma \cdot w h_{f}\right)$. As a result of the inclusion of the variable $H$, we are able to make a distinction between the effect of the individual's household input effort $(w h)$ and the effect of the provision level of the public good $H$ on the individual. Moreover, we assume that the utility effect of $H$ depends on the family size $f s$. More precisely, the spouse spending 20 hours on household production for a two-person family may derive less (or more) satisfaction from that effort than the spouse who spends 20 hours for a family with two children in addition to her husband. Therefore, we add an interaction term between family size and household hours. The ordinal utility functions of household members $i=m($ ale $), f($ emale) are then written as:

$$
\begin{aligned}
U_{i} & =\alpha_{i, 1} \ln (Y)+\left[\alpha_{i, 2}+\alpha_{i, 2 I} \ln (f s+1)\right] \cdot \ln (H)+\alpha_{i, 3} \ln \left(l e_{i}\right) \\
& +\alpha_{i, 4} \ln \left(w h_{i}\right)+\alpha_{i, 5} \ln \left(j h_{i}\right)
\end{aligned}
$$

where household income $Y$ equals:

$Y=w_{m}\left(T-l e_{m}-w h_{m}\right)+w_{f}\left(T-l e_{f}-w h_{f}\right)+y_{u}$

and the household care level $(H)$ is defined as:

$H=w h_{m}+\gamma \cdot w h_{f}$

while $y_{u}$ stands for non-labor income. We note that,as usual in these models, the utility functions have to be interpreted as describing a net of indifference curves. Hence, the analysis does not change if we apply a monotonic transformation on utility or normalize by requiring the coefficients to add up to 1 or another non-zero constant. 
According to the collective approach, we can describe household $n$ 's behavior as the outcome of maximizing a household utility function of the following type:

$$
U_{n, h}=\pi_{n} U_{n, m}+\left(1-\pi_{n}\right) U_{n, f}
$$

with respect to $l e_{m}, w h_{m}, l e_{f}$ and $w h_{f}$. The individual preferences are represented by $U_{n, i}$ and the utility weight is represented by $\pi_{n}$ with $0 \leq \pi \leq 1$. Furthermore, $\pi$ varies over households as a function of wages and possibly other variables that influence bargaining within the household. In addition, household members face the following constraints:

$$
\begin{aligned}
& l e_{i}+w h_{i}+j h_{i}=T \quad i=m, f \\
& Y=w_{m} \cdot j h_{m}+w_{f} \cdot j h_{f}+y_{u} \\
& H=w h_{m}+\gamma \cdot w h_{f}
\end{aligned}
$$

The parameter $\gamma$ stands for the productivity of the female in terms of male hours. The total weekly time endowment of 168 hours is denoted as $T$. The net wage rates of the male and the female are denoted by respectively $w_{m}$ and $w_{f}$. The $y_{u}$-term stands for the net weekly non-labor household income.

The $f s$-term in equation 1 , referred to as family size, stands for the number of children living in the household. In order to avoid taking a logarithm of zero we add one to the number of children.

For simplicity of exposition we start by assuming $\gamma=1$, and also assume for the individual utility functions, that $\sum \alpha_{i}=1$ for $i=m, f$ for identification purposes.

We now substitute the constraints into the utility functions. This yields for household $n$ the unconstrained problem:

$$
\max _{l e_{n, m}, w h_{n, m}, l e_{n, f}, w h_{n, f}} U_{n, h}=\pi_{n} U_{n, m}+\left(1-\pi_{n}\right) U_{n, f}
$$


with

$$
\begin{aligned}
U_{n, i} & =\alpha_{i, 1} \ln \left(w_{m} j h_{m}+w_{f} j h_{f}+y_{u}\right)+\left[\alpha_{i, 2}+\alpha_{i, 2 I} \ln (f s+1)\right] \cdot \ln \left(w h_{m}+w h_{f}\right) \\
& +\alpha_{i, 3} \ln \left(l e_{i}\right)+\alpha_{i, 4} \ln \left(w h_{i}\right)+\alpha_{i, 5} \ln \left(T-l e_{i}-w h_{i}\right)
\end{aligned}
$$

When the optimization problem is described in the Lagrangean form, it follows that the household utility function is concave, given explicit linear constraints. Hence, there exists one unique optimum. Assuming for the moment that $\pi_{n}$ is fixed, we get four first-order conditions.

Let us assume that the household sets the male's leisure time at $l e_{m}$, and his household production hours at $w h_{m}$, and, consequently, his job hours at $j h_{m}=\left(T-l e_{m}-w h_{m}\right)$, such that the collective utility function is maximized. Then after re-ordering, the corresponding first-order-conditions (FOCs) for the male's leisure time and hours of housework are :

$$
\begin{gathered}
\frac{\partial U_{h}}{\partial l e_{m}}=\frac{\partial U_{f}}{\partial l e_{m}}+\pi\left(\frac{\partial U_{m}}{\partial l e_{m}}-\frac{\partial U_{f}}{\partial l e_{m}}\right)=0 \\
\frac{\partial U_{h}}{\partial w h_{m}}=\frac{\partial U_{f}}{\partial w h_{m}}+\pi\left(\frac{\partial U_{m}}{\partial w h_{m}}-\frac{\partial U_{f}}{\partial w h_{m}}\right)=0
\end{gathered}
$$

For $l e_{f}$ and $w h_{f}$, we find two similar equations. We note that each of the FOCs in (4) and (5) consists of three terms. The first and the third term refer to the 'female' part of the collective utility function. The explanation for this is that the public goods $Y$ and $H$ figure in the utility functions of both partners. The hours $w h_{f}$ that the female works in the household affect the utility of the male. The same holds for the job working hours $j h_{f}$ of the female, because the net wage of the female is part of the household income.

There is no need to spell out all the FOCs in detail. Let us consider the first FOC in 
more detail. Obtaining the derivative $\frac{\partial U_{m}}{\partial l e_{m}}$ gives:

$$
\begin{aligned}
\frac{\partial U_{m}}{\partial l e_{m}} & =\frac{\alpha_{m, 1}}{w_{m} \cdot\left(T-l e_{m}-w h_{m}\right)+w_{f} \cdot\left(T-l e_{f}-w h_{f}\right)+y_{u}} \\
& +\frac{\alpha_{m, 3}}{l e_{m}}+\frac{\alpha_{m, 5}}{T-l e_{m}-w h_{m}}
\end{aligned}
$$

We see that this expression is linear in the 'male' utility parameters $\left(\alpha_{m}\right)$. The 'coefficients' $x$ are non-linear expressions in $l e_{m}, l e_{f}, w h_{m}, w h_{f}, w_{m}, w_{f}$. For instance, the first 'coefficient' may be denoted as $x_{1, m, 1}=\frac{1}{Y} \cdot{ }^{8}$ As $\alpha_{m, 2}$ does not appear in the first $F O C$, we have $x_{1, m, 2}=0$. For brevity, we denote the coefficient vector of the first $F O C$, referring to the male's utility function, by a 6 -vector function $x_{1, m}\left(l e_{m}, l e_{f}, w h_{m}, w h_{f}, w_{m}, w_{f}\right)$. We may write $\frac{\partial U_{m}}{\partial l_{m}}=x_{1, m}^{\prime} \alpha_{m}$. In a similar way we may derive $\frac{\partial U_{f}}{\partial l e_{m}}$, which may be written as $\frac{\partial U_{f}}{\partial l e_{m}}=x_{1, f}^{\prime} \alpha_{f}$.

Consequently, we may write the first FOC more concisely as:

$$
x_{1 f}^{\prime} \alpha_{f}+\pi\left(x_{1 m}^{\prime} \alpha_{m}-x_{1 f}^{\prime} \alpha_{f}\right)=0
$$

The index 1 refers to the $x$-vector in the first $F O C$. The other $F O C$ s with respect to $w h_{m}, l e_{f}$ and $w h_{f}$, can be written in a similar way. Hence, this yields a linear system of four equations

$$
\left[\begin{array}{cc}
\pi x_{1 m}^{\prime} & (1-\pi) x_{1 f}^{\prime} \\
\pi x_{2 m}^{\prime} & (1-\pi) x_{2 f}^{\prime} \\
\pi x_{3 m}^{\prime} & (1-\pi) x_{3 f}^{\prime} \\
\pi x_{4 m}^{\prime} & (1-\pi) x_{4 f}^{\prime}
\end{array}\right]\left[\begin{array}{l}
\alpha_{m} \\
\alpha_{f}
\end{array}\right]=\left[\begin{array}{ll}
\pi X_{m}^{\prime} & (1-\pi) X_{f}^{\prime}
\end{array}\right]\left[\begin{array}{l}
\alpha_{m} \\
\alpha_{f}
\end{array}\right]=0
$$

where $X_{m}^{\prime}$ and $X_{f}^{\prime}$ are $(4 \times 6)$-matrices. For household $n$, we define the $(4 \times 12)$-matrix $X_{n}^{\prime}$ by:

$$
\left[\pi_{n} X_{n, m}^{\prime} \quad\left(1-\pi_{n}\right) X_{n, f}^{\prime}\right]=X_{n}^{\prime}
$$

For convenience, we introduce the shorthand notation $z=\left(l e_{m}, w h_{m}, l e_{f}, w h_{f}\right)$ for the solu-

${ }^{8}$ Note that $Y=w_{m} \cdot\left(T-l e_{m}-w h_{m}\right)+w_{f} \cdot\left(T-l e_{f}-w h_{f}\right)+y_{u}$. 
tion vector. The left-hand-side of (7) is the gradient of the household utility function $U_{h}(z)$. We shall write it sometimes as the 4 -vector $U_{h}^{\prime}(z)$, or alternatively as $U_{z}$. The above system describes the equilibrium where the gradient vector equals the zero vector. Similarly, we will denote the $(4 \times 4)$-matrix of second-order derivatives of $U_{h}(z)$ by $U_{h}^{\prime \prime}$ or $U_{z z}$.

\section{Specification of the Pareto-weight}

The Pareto-weight distribution between the male and the female $(\pi, 1-\pi)$ is assumed to depend on their personal characteristics: in short, a vector $\left(v_{m}, v_{f}\right)$ of weight characteristics. As is mentioned by Browning et al. (2006), a model that makes use of a Pareto-weight is usually referred to as a collective model. They conclude that, when the Pareto-weight is not assumed to depend on prices (or, in our model, wages) then the model is equivalent to the standard unitary model. The dependency of the Pareto-weight function on wage rates is therefore a crucial element in our model.

In this paper the Pareto-weights will depend on the following distribution factors: the hourly wages of the two partners $\left(w_{m}, w_{f}\right)$, the number of children $(f s)$, the ages of the two partners $(a g e)$, and weekly non-labor income $y_{u} \cdot{ }^{9}$

Considering for the moment only the hourly wages of the two partners, we use the convenient functional specification:

$$
\pi_{n}(v)=N\left(\beta_{m} \ln \left(w_{n, m}\right)+\beta_{f} \ln \left(w_{n, f}\right)\right)
$$

where $N(\cdot)$ stands for the standard normal distribution function. The advantage of this specification by means of a distribution function is that $\pi(v) \in[0,1]$ always holds. If $\beta_{m}=$ $-\beta_{f}$ and $w_{m}=w_{f}$, we find $\pi(v)=\frac{1}{2}$. An increase of $\pi$ implies that the utility function of the male is weighted more heavily in the collective utility function at the expense of the utility of the female. The male's weight $\pi(v)$ is expected to be increasing in the male's wage

\footnotetext{
${ }^{9}$ We notice that the very presence of children might be the result of decisions regarding fertility that most likely reflect bargaining within the household. However, modelling the decision of having children is beyond the scope of the paper.
} 
and, inversely, is expected to be decreasing in the female's wage. Generally the weight will be asymmetric, except if $\beta_{m}=-\beta_{f}$ and $w_{m}=w_{f}$. If we add a constant $\beta_{0}$ to the argument in $N(\cdot)$, one of the partners is structurally overweighted. For example, if $\beta_{0}>0$, the utility function of the male is structurally overweighed. However, as in our empirical estimates we found a statistically insignificant value for $\beta_{0}$, we drop it from our model.

\section{The Estimation Method}

Let us assume we have a data set $\left\{l e_{m, n}, l e_{f, n}, w h_{m, n}, w h_{f, n}, w_{m, n}, w_{f, n}\right\}_{n=1}^{N}=\left\{z_{n}, w_{n}\right\}_{n=1}^{N}$ of $N$ observations of households $n$. Clearly, as econometricians usually do, we can try to

solve the system of FOCs for each $n$, yielding predicted values $\widehat{l e}_{m, n}, \widehat{l e}_{f, n}, \widehat{w h}_{m, n}, \widehat{w h}_{f, n}$ as functions of the individual wages $w_{m, n}, w_{f, n}$ and the unknown parameter vector $(\alpha, \beta)$. However, those functions would be highly non-linear in $\alpha$ and $\beta$, and consequently it would be difficult to estimate the unknown parameters. We propose a more convenient indirect estimation method, similar to the Wald-test criterion approach (see also Wales and Woodland (1983) and Blundell and Robin (1999)), in order to estimate the unknown parameter vector $(\alpha, \beta)$.

Consider the system:

$$
\left[\begin{array}{ll}
\pi_{n} X_{n, m}^{\prime} & \left(1-\pi_{n}\right) X_{n, f}^{\prime}
\end{array}\right]\left[\begin{array}{c}
\alpha_{m} \\
\alpha_{f}
\end{array}\right]=0 \quad \forall n
$$

where we assume for a start that the $\pi_{n}$ are known. We write:

$$
\left[\begin{array}{ll}
\pi_{n} X_{n, m}^{\prime} & \left(1-\pi_{n}\right) X_{n, f}^{\prime}
\end{array}\right]=X_{n}^{\prime}
$$

Obviously the matrix equality (10) will not hold exactly; so we assume

$$
X_{n}^{\prime} \alpha=\varepsilon_{n}
$$


where we introduce the error vector $\varepsilon \sim N\left(0, \Sigma_{\varepsilon}\right)$, and we assume that the behavior of households is not correlated, that is, $E\left(\varepsilon_{n}, \varepsilon_{n^{\prime}}\right)=0$ if $n \neq n^{\prime}$. The $(4 \times 4)$-error-covariance-matrix $\Sigma_{\varepsilon}$ may be non-diagonal in order to include the possibility that errors in time-use decisions are correlated. Given the overall time budget constraints and the probable correlation between the partners' decisions, such a correlation is probable.

The obvious way to estimate this system is to minimize the sum of squared residuals $\sum_{1}^{N} \varepsilon_{n}^{\prime} \Sigma_{\varepsilon}^{-1} \varepsilon_{n}=\sum_{1}^{N} \alpha^{\prime} X_{n} \Sigma_{\varepsilon}^{-1} X_{n}^{\prime} \alpha$ with respect to $\alpha$. We exclude the 'trivial' solution $\alpha=0$ by adding the two identifying conditions $\sum \alpha_{m}=1$ and $\sum \alpha_{f}=1$.

The estimation problem is solved by iteration. We start by assuming $\beta_{m}=\beta_{f}=1$, yielding first-round Pareto-weight coefficients $\pi_{n}^{(1)}$. Note that these Pareto-coefficients are not constant, as households differ with respect to wages $w_{m}$ and $w_{f}$. Then we estimate the $\alpha$ 's, given $\pi_{n}^{(1)}$.

Consider the system of four equations:

$$
y_{n}=X_{n}^{\prime} \alpha+\varepsilon_{n}
$$

where we introduce the nuisance vector $y_{n}$. Surprisingly, the system can be estimated in a simple way by the method of Seemingly Unrelated Least Squares (SUR). If we set $y_{n}=0$ for all $n$, estimation of this system under the constraints $\sum \alpha=1$ is equivalent to minimizing $\sum_{1}^{N} \alpha^{\prime} X_{n} \Sigma_{\varepsilon}^{-1} X_{n}^{\prime} \alpha$ with respect to $\alpha$ under the constraints.

The estimation of the collective model is somewhat more complex, as we have to estimate the parameters $\beta_{m}, \beta_{f}$ as well, which requires a non-linear estimation method. On the basis of the first-round estimate $\alpha^{(1)}$, we estimate $\beta_{m}^{(1)}, \beta_{f}^{(1)}$. Using these estimated $\beta$-values, we then obtain $\pi^{(2)}$. With $\pi^{(2)}$ we estimate $\alpha^{(2)}$, and we continue this iterative process until convergence is reached.

The asymptotic covariance matrix $\Sigma_{\alpha, \beta}$ of the parameter estimates $(\widehat{\alpha}, \widehat{\beta})$ is derived in the usual way. 


\section{Data and Estimation Results}

We use the 2003-wave ( $l$ ) of the British Household Panel Survey (BHPS), where we consider a subset of 1497 two-earner households. These households were interviewed between September 2002 and September 2003. The BHPS started in 1991 and is household-based; each adult member of the household is interviewed each year. The main objective of the BHPS is to give insight into the social and economic changes at the individual and household levels in the UK.

The information that is used for this study has been derived from questions on how individuals of two-earner households allocate their time. From the proposed empirical model it follows that we are interested in the number of hours that individuals spend on leisure, household tasks, and on their jobs.

Table 1 shows the summary statistics on the weekly hours spent on these different activities by males and females. Furthermore, Table 1 shows the net hourly wage rates of males and females. The non-labor household income $y_{u}$ is defined as the sum of weekly income from social benefits, income from investments and transfer income. By the latter, we mean income that is transferred from one household to another household (for example, gifts from parents to their children). Our data set, unfortunately, does not allow us to make a clear distinction between the origins of the unearned income.

\section{-Insert Table 1 about here-}

As expected, the descriptive statistics indicate that men earn a higher wage than women, and spend more time on paid labor than women, while the opposite is true for the time spent on household activities.

In the BHPS we have information on the hours that household members spend on household activities. The specific question is: "about how many hours do you spend on housework in an average week, such as time spent on cooking, cleaning and doing the laundry?". While cooking, doing the laundry and cleaning are activities that are explicitly stated in the question, the addition of such as shows that we can not be certain how housework is exactly 
defined. It is likely that housework captures the time spent on the explicitly stated activities, but there may be more, such as child care. Consequently, the distinction between housework and leisure may be ambiguous, and therefore we leave the empirical definition to the respondents themselves. Some love cooking and others hate it. For the former it is a leisure activity, and for the latter it is work.

An important issue is that there is no certainty whether respondents consider child care as housework or leisure. For child care we leave the implicit classification to the respondent as well. Furthermore, these activities depend very much on the number of children.

Given the observed quantities of time that are allocated to certain activities, and assuming that individuals maximize their utility following the collective model we can estimate the preference parameters $\left(\alpha_{m}, \alpha_{f}\right)$. At this point we wish to introduce some more flexibility with respect to the parameter $\gamma$, which up to now we assumed to equal 1 for convenience. For the estimation we will distinguish four different alternatives:

- Alternative 1: $\gamma=1$ and $\alpha_{i, 2 I}=0,(i=1,2)$.

- Alternative 2: $\gamma=1$ and $\alpha_{i, 2 I}$ to be estimated

- Alternative 3: $\gamma$ to be estimated and $\alpha_{i, 2 I}=0$

- Alternative 4: $\gamma$ to be estimated and $\alpha_{i, 2 I}$ to be estimated.

While we assume for Alternatives 1 and 2 that $\gamma=1$ and consequently that the number of household hours of male and female are perfect substitutes, this assumption is relaxed in Alternatives 3 and 4 . For the second and fourth alternative an interaction term is included.

Table 2 presents the parameter estimates for $\left(\alpha_{m}, \alpha_{f}\right)$.

-Insert Table 2 about here-

We note that the FOCs with respect to $w h_{i}$ are not linear in $\gamma$ and therefore we estimate the $\gamma$ parameter numerically. We let $\gamma$ vary with a grid-width of 0.025 , and for each alternative value of $\gamma$, choose that value of $\gamma$ that gives the highest log-likelihood of the system. The differences in log-likelihood between the four different alternatives are non-significant. 
The $\gamma$-parameters are 0.85 and 0.925 for Alternatives 3 and 4, respectively, and hence the marginal rate of substitution is smaller than 1 . The explanation for this result might be explained by the fact that, since women on average spend more time on household tasks than men, the female's marginal household work productivity may be somewhat less than that of the male. Men may be more efficient when spending an additional hour on household tasks. We note that $\gamma$ should be interpreted as the ratio of marginal productivities.

When concentrating on the preference parameters, we note that the interaction parameter drops out of the model for Alternatives 1 and 3 and hence there are no estimation results for the interaction of family size with the total household production. We see that all parameter values are significant except the interaction effect of total household production with family size for the male in Alternatives 2 and 4.

The estimation results appear to be robust for the different alternatives ${ }^{10}$. The main variables in the utility function for the four different alternatives appear to be leisure and household income, for both the male and the female. The preference for total household production is influenced by family size for the female, while this is not the case for the male.

A Wald test is performed in order to test whether the preference parameters of men and women are on average equal. The test results are printed in Table 3:

\section{-Insert Table 3 about here-}

An $x$-sign indicates that the parameters are significantly different from one another, while a 0-sign indicates that the parameters do not significantly differ. The test reveals that the coefficients for males and females are, in general, significantly different. The exceptions are the preference parameters for household work in Alternative 1 and the preference parameters for joint household production in Alternatives 2 and 4 .

We see that male and female leisure are the most important variables by far, followed by household income. The male is more income-oriented than the female and vice versa for leisure. Job working hours are negative for both, but more so for the male. Finally,

\footnotetext{
${ }^{10}$ Actually, the results are sometimes incredibly robust, with a t-ratio of 256 . As all estimates are plausible, and we have tested several other specifications, we could do nothing other than accept this robustness.
} 
housework has a weakly positive effect, where the female derives somewhat more satisfaction from it than the male.

In order to obtain some more insight into the estimates of Table 2 , we can derive the marginal rate of substitution between leisure hours and job hours for the male and the female separately. Since the estimates of the coefficients for the four different alternatives are quite similar, we will only derive the marginal rate of substitution between leisure hours and job hours for Alternative 1. The marginal rates of substitution for the other three alternatives are approximately equal. The marginal rate of substitution between leisure hours and job hours for the male is found from the equation:

$$
\frac{\partial U_{m}}{\partial l e_{m}} \cdot \Delta l e_{m}+\frac{\partial U_{m}}{\partial j h_{m}} \cdot \Delta j h_{m}=0
$$

From (13) we can derive:

$$
\frac{\alpha_{m, 1} w_{m}}{Y} \cdot \Delta j h_{m}+\frac{\alpha_{m, 3}}{l e_{m}} \cdot \Delta l e_{m}+\frac{\alpha_{m, 5}}{j h_{m}} \cdot \Delta j h_{m}=0
$$

From Table 1 we can obtain the average net hourly wage of the male (7.947 pound) and the average net household income per week $(£ 349+£ 209=£ 558)$. From Table 2 we obtain the estimates of the preference parameters and we find:

$$
\frac{0.261 \cdot 7.947}{349+209} \cdot \Delta j h_{m}+\frac{0.755}{119} \cdot \Delta l e_{m}+\frac{-0.033}{44} \cdot \Delta j h_{m}=0
$$

Rewriting 15 gives:

$$
0.006 \cdot \Delta l e_{m}+(0.004-0.001) \Delta j h_{m}=0
$$

It follows that the (marginal) shadow price of one leisure hour is worth about $\frac{1}{2}$ a job hour, and accordingly its money value would be about $\frac{1}{2}$ the male 's hourly wage. Doing the same for females, we find that the (marginal) shadow price of one hour of female leisure is worth about $\frac{1}{7}$ of a job hour and its money value is $\frac{1}{7}$ of the female's hourly wage.

In Table 4 we present the parameters of the Pareto-weight function for the different 
Alternatives 1-4, where we add the distribution factors children and age. We see that the hourly wage rates are by far the most important. The weight of the male's wage is about equal to that of the female, while the sign of the female coefficient is negative, as we expected. The utility of the female is weighted more heavily if there are children in Alternative 1, where children below age 5 get more weight compared with children of 5 years and older, while the effect of children above 11 years is non-significant. Indeed, it may be expected that in traditional households the bargaining power of the female increases with the presence of young children. This child effect is also found for the other alternatives, but there it is non-significant.

The non-labor household income is slightly significant for the first alternative and nonsignificant in all other alternatives.

The average (male) Pareto-weight coefficient $\left(\bar{\pi}_{n}\right)$ is slightly higher than 0.5 for Alternative 1, 3 and 4 . For the Alternative 2 it is just below 0.5. In general it seems that the Pareto-weight distribution in British households is on average about 50-50 for the male and the female within the two-earner households.

We note that the chosen functional form of the Pareto-weight function allows for all sample average values between 0 and 1. The Pareto-weight effects are based on a sub-sample of two-earner households, and so it is possible that the average value of the Pareto-weight coefficient will be different for one-earner households. In Figure 1 we depict the distribution density function of $\pi_{n}$ over the sample for the different Alternatives 1-4.

\section{-Insert Figure 1 about here-}

Figure 1 shows that, although on average the Pareto-weight is equally divided between the male and the female, there is much variation in the distribution of Pareto-weight between individual households.

\section{-Insert Table 4 about here-}

We conclude that the Pareto-weight distribution seems to be dominated by the ratio of hourly wages $\frac{w_{m}}{w_{f}}$, where $\beta_{m}$ and $\beta_{f}$ are about equal. This is empirical evidence for the idea 
that bargaining power in marriage is determined by differences in (potential) wage rates. This was also suggested by Pollak (2005).

The child effect is significant when the household preference parameter does not depend on family size, and when we do not allow for gender differences in household productivity. However, when the preference for joint household production also depends on family size, the female tends to weight the total household production more heavily when family size increases. We do not find this effect for males. The child effect in the Pareto-weight function then becomes non-significant. Furthermore, when we allow for differences in the marginal productivity between men and women we also find that the children effects does not significantly influence the Pareto-weight distribution. Hence, it seems that the child effect that is found for the Alternative 1 is captured by the effects of family size and gender differences in household productivity for the other alternatives.

Finally, we present a 'typical' variance-correlation matrix of the error vector in Table 5. This matrix is a mixture of a covariance- and a correlation- matrix. The diagonal cells contain variances, while the off-diagonal cells contain correlation ratios. Using the relation $\sigma_{i j}=\rho_{i j} \sqrt{\sigma_{i i} \cdot \sigma_{j j}}$ we may retrieve the covariances. The matrix Table 5 refers to the case $\gamma=1$. The variance-correlation matrix does not change much over the different $\gamma$ specifications. The matrix below shows clearly that the error-terms are correlated.

-Insert Table 5 about here-

\section{$5 \quad$ Wage, child and substitution effects}

In this model $w_{m}$ and $w_{f}$ are considered to be exogenous. Now we consider the question how labor supply and leisure consumption react on wage changes.

Let us assume that the wage vector $\left(w_{m}, w_{f}\right)=w$ changes by $\Delta w$. Then what will be the change in $z(w)$ ? We return to the system in $(7)$ and assume that $w^{(0)}, z^{(0)}$ represents the situation ex ante, and that $w^{(1)}, z^{(1)}$ is the new equilibrium after the change of wages.

We notice that the $(4 \times 12)$-matrix $X$ is a function of $w$. Hence, differentiating the 
elements of the matrix $X$ also with respect to $w$, we add two columns to the matrix $U_{z z}$, producing the $(4 \times 6)-$ matrix $\left(U_{z z} \quad U_{z w}\right)$. The matrix $U_{z w}$ is a $(4 \times 2)-$ matrix. According to equation (2), $\frac{\partial U_{h}}{\partial z}=\pi \frac{\partial U_{m}}{\partial z}+(1-\pi) \frac{\partial U_{f}}{\partial z}=0$. We have to take into account that $\pi$ depends on the wage vector as well, and hence:

$$
\begin{aligned}
U_{z z} & =\pi \cdot U_{m, z z}+(1-\pi) \cdot U_{f, z z} \\
U_{z w} & =\pi \cdot U_{m, z w}+(1-\pi) U_{f, z w}+\left[U_{m, z}-U_{f, z}\right]\left[\frac{\partial \pi}{\partial w}\right]^{\prime}
\end{aligned}
$$

where the last element is the product of a $(4 \times 1)$ - matrix and a $(1 \times 2)$-matrix, resulting in a $(4 \times 2)$ - matrix.

Denoting $z^{(1)}-z^{(0)}=\Delta z$, the new equilibrium has to satisfy the equation:

$$
U_{z z} \Delta z+U_{z w} \Delta w=0
$$

and hence the wage effect matrix is:

$$
\frac{\partial z}{\partial w}=-\left(U_{z z}\right)^{-1}\left[\pi U_{m, z w}+(1-\pi) U_{f, z w}+\left[U_{m, z}-U_{f, z}\right]\left[\frac{\partial \pi}{\partial w}\right]^{\prime}\right]
$$

The effect may be split into a usual gross substitution effect and a separate 'power' shift effect. Because of the identity $j h+w h+l e \equiv 24$, we find for the effects on job hours of the male and the female:

$$
\frac{\partial j h_{m}}{\partial w}=-\left(\frac{\partial w h_{m}}{\partial w}+\frac{\partial l e_{m}}{\partial w}\right)
$$

and

$$
\frac{\partial j h_{f}}{\partial w}=-\left(\frac{\partial w h_{f}}{\partial w}+\frac{\partial l e_{f}}{\partial w}\right)
$$

The corresponding elasticities are $\frac{\partial j h}{\partial w} \cdot \frac{w}{j h}$. The analysis was performed under the assumption that households were in equilibrium in $z^{(0)}$. The elasticities in the sample average, that is all matrices evaluated in the sample mean, are presented in Table 6.

-Insert Table 6 about here- 
Table 6 indicates that there is both household members have a backward-bending laborsupply curve. The income effect dominates the substitution effect. When the hourly wage rate increases, individuals tend to substitute paid labor hours for leisure. This effect is more pronounced for the female partner than for the male. The average wage elasticities are strongly influenced by the interaction effect. Letting the preference for joint household production depend on family size, the average wage elasticities are more negative for the male ( -0.994 for Alternative 2 and -1.019 for Alternative 4) and less negative for the female ( -0.591 for Alternative 2, and even -0.048 for Alternative 4).

The labor-supply curve in terms of the hourly wage rate of the partner is forward-bending. It appears that individuals tend to replace leisure hours by paid job hours when the wage of their partner increases. With the exception of Alternative 2, the empirical results also suggest that individuals replace leisure hours by household production hours when the hourly wage of the partner increases. When women contribute more in terms of money, the husband is motivated to keep up with her in terms of effort in earning money and by becoming more productive in the household. The same holds vice versa. From a bargaining perspective, it may be the case that, if the bargaining position of the female is improved due to her wage increase, the male supplies more hours of labor to maintain his bargaining position in terms of his contribution to household income within the household.

In general, the estimation results suggest that the income effect dominates the substitution effect when the hourly wage rate increases. The relative 'power' of the individual, whose wage increases, is increased; as a result he/she tends towards a more favorable time allocation scheme, while the partner shifts towards a more unfavorable time allocation scheme.

As we consider a sample of two-earner households, this might considerably influence the results. By considering only two-earner households, we do not consider the initial choice of whether a partner participates in the labor market at all. We merely observe the outcome of this decision process for the case where both partners do participate on the labor market. For these households, household income is on average higher, and as a consequence we might find a backward-bending labor supply curve for both household members. 
On the basis of the estimation results of the last section and the wage effects, the unitary model is rejected in favor of the collective model. The empirical results suggest that the preference parameters of the male and the female differ significantly and that the Paretoweight distribution is significantly influenced by the difference in wage rates. Furthermore, a wage rate increase of the male is differently compensated by the female in terms of labor hours, and vice versa (i.e. the Slutsky symmetry condition does not hold).

We assume that household income consists of three components: namely, the labor income of male and female and an additional unearned income $y_{u}$. The additional unearned income is defined as the net non-labor income earned last week. Hence, it is possible to obtain the unearned income effects:

$$
\frac{\partial z}{\partial y_{u}}=-\left(U_{z z}\right)^{-1}\left[U_{f, z y_{u}}+\pi \cdot\left(U_{m, z y_{u}}-U_{f, z y_{u}}\right)+\left[U_{m, z}-U_{f, z}\right] \frac{\partial \pi}{\partial y_{u}}\right]
$$

We see that an additional household income increase has an effect on all time variables simultaneously. The unearned income effects may be derived in the usual way and the results are shown in Table 7 .

\section{-Insert Table 7 about here-}

The distribution of $y_{u}$ in the sample is heavily skewed to the right or, in other words, the median value $y_{u}$ is smaller than the average value of $y_{u}$. Most households do not 'earn' much non-labor household income. Table 7 suggests for all alternatives that an increase of household income due to unearned income induces a shift to more leisure hours for male and female, although the effect is small. The opposite effect is found for paid job hours with the exception of the female job hour effect for Alternative 1. The effect on household production hours is ambiguous.

Unfortunately, the data do not provide information on who is the provider of the nonlabor income. Hence, it is impossible to split $y_{u}$ into a male and a female part. 
We may also assess the effect of having children using equation (19):

$$
\frac{\partial z}{\partial \ln (f s)}=-\left(U_{z z}\right)^{-1}\left[\left[\frac{\partial \pi}{\partial \ln (f s)}\right]\left[U_{m, z}-U_{f, z}\right]\right]
$$

The estimates are presented Table 8.

\section{-Insert Table 8 about here-}

The columns indicate the number of children between certain age levels. For instance, c02 refers to the number of children present in the household who are aged between zero and two, and so on.

We see that the effect of young children is considerable but that the effect for children above 5 years of age is not very robust. The child effect will most likely be different if one-earner households were considered as well. Clearly these effects will be affected by the British organisation of school times and childcare.

It appears that women tend to work fewer hours on the labor market when there are more children present in the household younger than 5. Men, on the other hand, tend to do the opposite. When there are more young children in the household, women usually specialize in household tasks, while men specialize in labor market tasks. Hence, women replace paid labor hours by household production hours, and men replace their leisure time with job market hours.

\section{Conclusion}

In this paper we estimate the separate utility functions of male and female household members on the basis of a public good version of the collective household model. By assuming that each spouse's leisure is an exclusive good the model is non-parametrically identified, as is theoretically shown by Chiappori \& Ekeland (2006).

We find that the ordinal utility functions of males and females, and consequently their indifference curves, are significantly different. This provides additional evidence for the 
collective approach. Although the model is non-linear in the outcome variables male leisure, female leisure, and so on, it appears possible to estimate the utility parameters by means of a simple Seemingly Unrelated Regression approach.

We estimated four alternative models. For Alternatives 1 and 2, it is assumed that the number of household hours of male and female are perfect substitutes; this assumption is relaxed in Alternatives 3 and 4. For Alternatives 2 and 4 an interaction term is included, where joint household production interacts with family size, while we assume that there is no interaction effect in Alternative 1 and 3.

The estimation results appear to be fairly robust for the different Alternatives 1-4. When we do not postulate that household hours of the male and the female are perfect substitutes, we find that the male is slightly more efficient in performing (his) household tasks. The explanation for this might be that the female spends, on average, more time on household tasks than men. One additional hour on household production of the female might then be less productive compared with one additional hour of household production hour by the male. Note that this is a comparison at the margin.

The most important variables in the utility function appear to be leisure and household income, for both male and female. When we assume that the preference for total household production is influenced by family size, we find for the female utility function that this preference is influenced by family size, but this effect is not found for the male.

The negative values of own-wage labor supply elasticities imply that both partners have a backward-bending labor supply curve; we note that for females this result differs from historical results. We conclude, therefore, that the labor supply curve of women tends to resemble that of men. An explanation for the backward-bending labor supply curve for women is that there are now more women with a high income than in the past. For these women, apparently, the income effect dominates the substitution effect, meaning that they reduce their hours of work rather than increasing them when their own wage rate increases.

Research on female labor supply conducted in the 1980s and 1990s generally found high wage elasticities. Typically, a wage elasticity of around 1 was found. Furthermore, the 
female labor supply curve was forward-bending for the entire range of female wages (see Killingsworth \& Heckman (1986)). That seems to have changed over time because of the increase in female labor supply and the changed attitude towards female labor participation. Apparently women's behavior on the labor market nowadays resembles that of men, although the descriptive statistics still indicate that the hourly wage rate and the amount of labor supply is, on average, lower for females compared with males.

We also explained the Pareto-weight distribution within the household. We find for this sample of two-earner households that the weight is about evenly distributed between the partners. Still there is considerable variation between households. The Pareto-weight distribution depends mainly on the relative hourly wages (earning potential). The relative weight of the female compared with that of her partner is increased if there are young children in the household, when we assume that there is no family size interaction with household production and that the household hours of the male and the female are perfect substitutes. When we relax these assumptions the child effect disappears.

The model discussed in this paper can be extended in several ways. First, it seems interesting to examine how results vary with different model specifications. Second, it might be that other characteristics are important when discussing the division of labor and household tasks, which in its turn influence the power distribution. Third, we only considered the special sub-sample of two-earner households. This simplified the analysis considerably, as one-earner families reflect a corner solution of the household decision problem. Fourth, it would be interesting to estimate a collective model of time allocation over time, since it is then possible to observe changes in the division of labor and household tasks due to household specific events. 


\section{References}

Apps, P. \& R. Rees (1988), 'Taxation and the household', Journal of Public Economics 35, 355-369.

Apps, P. \& R. Rees (1997), 'Collective labor supply and household production', Journal of Political Economy 105, 178-190.

Apps, P. \& R. Rees (1999), 'Individual versus joint taxation in models with household production', Journal of Political Economy 107, 393-403.

Becker, G. S. (1965), 'A theory of the allocation of time', The Economic Journal 75, 493-517.

Becker, G.S. (1991), A Treatise on the Family, Enl. Edition, Cambridge University Press.

Blundell, R. \& J.M. Robin (1999), 'An iterated least squares estimator for conditionally linear equations models', Journal of Applied Econometrics 14(3), 209-232.

Blundell, R., P.A. Chiappori, T. Magnac \& Costas Meghir (2007), 'Collective labor supply: Heterogeneity and nonparticipation', Review of Economic Studies 74, 417-445.

Browning, M., F, Bourguignon, P. A. Chiappori \& V. Lechene (1994), 'Income and outcomes: A structural model of intrahousehold allocation', The Journal of Political Economy 102(6), 1067-1096.

Browning, M. \& M. Gørtz (2005), Spending time and money within the household. working paper Institute of Economics, Copenhagen.

Browning, M. \& P.A. Chiappori (1998), 'Efficient intra-household allocations: A general characterization and empirical tests', Econometrica 66(6), 1241-78.

Browning, M., P.A. Chiappori \& Valerie Lechene (2006), 'Collective and unitary models: A clarification', Review of Economics of the Household 4, 5-14.

Carlin, P. (1990), 'Intra-family bargaining and time allocation', Research in Population Economics 7, 215-243. 
Chiappori, P. A. (1988), 'Rational household labor supply', Econometrica 56(1), 63-90.

Chiappori, P. A. (1992), 'Collective labor supply and welfare', The Journal of Political Economy 100, 437-467.

Chiappori, P. A. (1997), 'Introducing household production in collective models of labor supply', The Journal of Political Economy 105(1), 191-209.

Chiappori, P. A. \& I. Ekeland (2006), The micro economics of efficient group behavior: Identification. Mimeo, University of Chicago.

Chiappori, P.A., B. Fortin \& G. Lacroix (2002), 'Marriage market, divorce legislation, and household labor supply', Journal of Political Economy 110(1), 37-72.

Couprie, H. (2007), 'Time allocation within the family: Welfare implications of life in a couple', The Economic Journal 117, 287-305.

Donni, O. (2008), Household behavior and family economics, in W.-B. Zhang, eds., The Encyclopedia of Life Support Systems, Publishers, Oxford,UK.

Donni, O. \& N. Moreau (2007), 'Collective labor supply: A single-equation model and some evidence from french data', Journal of Human Resources 42(1), 214-246.

Duguet, E. \& V. Simonnet (2007), 'Labor market participation in france: an aymptotic least squares analysis of couples'decisions', Review of Economics of the Household 5(2), 159179.

Fortin, B. \& G. Lacroix (1997), 'A test of the unitary and collective models of household labor supply', The Journal of Political Economy 107(443), 933-956.

Grossbard, A. (1976), 'An economic analysis of polygamy: The case of maiduguri', Current Anthropology 17, 701-707.

Grossbard, S (2005), 'Women's labor supply, marriage, and welfare dependency', Labour 19, 211-241. 
Grossbard-Shechtman, A. (1984), 'A theory of allocation of time in markets for labor and marriage', Economic Journal 94, 863-882.

Killingsworth, M.R. \& J.J. Heckman (1986), Female Labor Supply: A Survey, Handbook of Labor Economics, Vol.1, (North Holland: Amsterdam), pp. 103-204.

Kooreman, P. \& A. Kapteyn (1987), 'A disaggregated analysis of the allocation of time within the household', The Journal of Political Economy 95(2), 223-249.

Lancaster, K. (1966), 'A new approach to consumer theory', The Journal of Political Economy $\mathbf{7 4}(2), 132-157$.

Lundberg, S., R. Pollak \& T.J. Wales (1997), 'Do husbands and wives pool their resources? Evidence from the U.K. child benefit', Journal of Human Resources 32(3), 463-480.

McElroy, M. (1990), 'The empirical content of nash bargained household behavior', The Journal of Human Resources 25(4), 559-583.

Mincer, J. (1963), Market Prices, Opportunity Costs, and Income Effect, In: C. Christ (ed.), Measurement in Economics, Stanford, CA: STanford University Press, pp. 36-52.

Pollak, R. A. (2005), 'Bargaining power in marriage: Earnings, wage rates and household production', NBER Working paper .

Rapoport, B., C. Sofer \& A. Solaz (2005), Household production in a collective model: Some new results. Cahiers de la MSE, srie blanche.

Thomas, D. (1990), 'Intra household resource allocation: An inferential approach', Journal of Human Resources 25(4), 635-664.

Vermeulen, F. (2002), 'Collective household models: principles and main results', Journal of Economic Surveys 16(4), 534-564.

Wales, T.J. \& A.D. Woodland (1983), 'Estimation of consumer demand systems with binding non-negativity constraints', Journal of Econometrics 21(3), 263-285. 
Table 1: Summary Statistics

\begin{tabular}{lccccc}
\hline \hline & \#obs. & mean & Std. Dev. & $\begin{array}{c}10 \% \\
\text { percentile }\end{array}$ & $\begin{array}{c}90 \% \\
\text { percentile }\end{array}$ \\
& & & & & \\
Leisure hours male & 1497 & 118.742 & 9.470 & 107 & 128 \\
Household hours male & 1497 & 5.328 & 4.205 & 1 & 10 \\
Job hours male & 1497 & 43.931 & 8.953 & 37 & 55 \\
Leisure hours female & 1497 & 121.707 & 11.616 & 108 & 137 \\
Household hours female & 1497 & 13.917 & 8.548 & 5 & 25 \\
Job hours female & 1497 & 32.376 & 11.460 & 16 & 45 \\
& & & & & \\
Hourly wage male & 1497 & 7.947 & 8.526 & 4.50 & 11.67 \\
Hourly wage female & 1497 & 6.450 & 2.894 & 3.75 & 9.93 \\
Unearned income & 1497 & 40.627 & 73.420 & 0 & 834.46 \\
\hline \hline
\end{tabular}


Table 2: Parameter estimates for $\alpha$

\begin{tabular}{|c|c|c|c|c|}
\hline \multirow[t]{2}{*}{ Alternative 1} & \multicolumn{2}{|c|}{ Male } & \multicolumn{2}{|c|}{ Female } \\
\hline & Estimate & $t$-value & Estimate & $t$-value \\
\hline leisure & 0.755 & 256.33 & 0.778 & 213.67 \\
\hline housework & 0.003 & 20.93 & 0.004 & 7.3 \\
\hline household production $(H)$ & 0.014 & 7.73 & 0.032 & 15 \\
\hline$H$ interaction term & . & 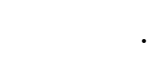 & & \\
\hline household income & 0.261 & 57.33 & 0.204 & 60.23 \\
\hline job working hours & -0.033 & -13.29 & -0.017 & -21.59 \\
\hline \multirow[t]{2}{*}{ Alternative 2} & \multicolumn{2}{|c|}{ Male } & \multicolumn{2}{|c|}{ Female } \\
\hline & Estimate & $t$-value & Estimate & $t$-value \\
\hline leisure & 0.757 & 219.190 & 0.823 & 193.330 \\
\hline housework & 0.004 & 23.510 & 0.002 & 3.840 \\
\hline household production $(H)$ & 0.013 & 6.010 & 0.019 & 9.700 \\
\hline$H$ interaction term & 0.002 & 0.570 & 0.013 & 3.910 \\
\hline household income & 0.293 & 61.690 & 0.180 & 54.720 \\
\hline job working hours & -0.069 & -26.470 & -0.037 & -29.140 \\
\hline \multirow[t]{2}{*}{ Alternative 3} & \multicolumn{2}{|c|}{ Male } & \multicolumn{2}{|c|}{ Female } \\
\hline & Estimate & $t$-value & Estimate & $t$-value \\
\hline leisure & 0.739 & 259.590 & 0.794 & 224.260 \\
\hline housework & 0.003 & 17.360 & 0.006 & 13.830 \\
\hline household production $(H)$ & 0.026 & 15.490 & 0.016 & 7.990 \\
\hline \multicolumn{5}{|l|}{$H$ interaction term } \\
\hline household income & 0.268 & 62.220 & 0.203 & 61.730 \\
\hline job working hours & -0.036 & -15.540 & -0.019 & -23.930 \\
\hline \multirow[t]{2}{*}{ Alternative 4} & \multicolumn{2}{|c|}{ Male } & \multicolumn{2}{|c|}{ Female } \\
\hline & Estimate & $t$-value & Estimate & $t$-value \\
\hline leisure & 0.741 & 237.250 & 0.767 & 206.160 \\
\hline housework & 0.003 & 19.070 & 0.005 & 11.160 \\
\hline household production $(H)$ & 0.020 & 9.130 & 0.015 & 6.080 \\
\hline$H$ interaction term & 0.005 & 1.150 & 0.028 & 6.380 \\
\hline household income & 0.269 & 62.160 & 0.203 & 59.650 \\
\hline \multirow[t]{2}{*}{ job working hours } & -0.037 & -15.640 & -0.018 & -23.900 \\
\hline & Alt. 1 & Alt. $\mathscr{2}$ & Alt. 3 & Alt. 4 \\
\hline $\bar{\pi}$ & 0.532 & 0.471 & 0.542 & 0.534 \\
\hline$\gamma$ & 1 & 1 & 0.85 & 0.925 \\
\hline $\mathrm{N}$ & 1497 & 1497 & 1497 & 1497 \\
\hline
\end{tabular}


Table 3: 'Joint' Wald test to test equality of preference parameters

\begin{tabular}{lcccc} 
& \multicolumn{5}{c}{ Prob $>\chi^{2}$} \\
\cline { 2 - 5 } Preference parameter w.r.t & Alt. 1 & Alt. 2 & Alt. 3 & Alt. 4 \\
\hline Leisure & $\mathrm{x}$ & $\mathrm{x}$ & $\mathrm{x}$ & $\mathrm{x}$ \\
housework & 0 & $\mathrm{x}$ & $\mathrm{x}$ & $\mathrm{x}$ \\
Joint household production $(H)$ & $\mathrm{x}$ & 0 & $\mathrm{x}$ & 0 \\
$H$ interaction term &. & $\mathrm{x}$ &. & $\mathrm{x}$ \\
Household income & $\mathrm{x}$ & $\mathrm{x}$ & $\mathrm{x}$ & $\mathrm{x}$ \\
Job working hours & $\mathrm{x}$ & $\mathrm{x}$ & $\mathrm{x}$ & $\mathrm{x}$ \\
\hline \hline
\end{tabular}

Note: $\mathrm{x}$ indicates that the preference parameter of male and female differ significantly, 0 indicates that this is not the case 
Table 4: Estimates of the Power Function $\pi_{n}$

\begin{tabular}{|c|c|c|c|c|}
\hline & \multicolumn{2}{|c|}{ Alternative 1} & \multicolumn{2}{|c|}{ Alternative 2} \\
\hline & Estimate & t-value & Estimate & t-value \\
\hline $\log \left(w_{\text {male }}\right)$ & $0.593^{* * *}$ & 25.710 & $0.592^{* * *}$ & 22.620 \\
\hline $\log \left(w_{\text {female }}\right)$ & $-0.562^{* * *}$ & -25.260 & $-0.606^{* * *}$ & -23.260 \\
\hline $\log (\#$-children $0 / 2+1)$ & $-0.094^{* *}$ & -2.320 & -0.078 & -1.650 \\
\hline $\log (\#$-children $3 / 4+1)$ & $-0.091^{* *}$ & -2.170 & -0.062 & -1.270 \\
\hline $\log (\#$-children $5 / 11+1)$ & $-0.056^{* *}$ & -2.370 & -0.023 & -0.860 \\
\hline $\log (\#$-children $12 / 16+1)$ & -0.038 & -1.320 & 0.011 & 0.340 \\
\hline $\log (\#$-children $>16+1)$ & -0.052 & -0.980 & 0.002 & 0.040 \\
\hline $\log \left(\right.$ age $\left.e_{\text {male }}\right)$ & 0.014 & 0.210 & -0.056 & -0.710 \\
\hline $\log \left(\right.$ age $\left._{\text {female }}\right)$ & -0.036 & -0.520 & 0.019 & 0.240 \\
\hline $\log \left(y_{u}+1\right)$ & $0.010^{*}$ & 1.750 & -0.004 & -0.540 \\
\hline \multirow[t]{3}{*}{$\mathrm{N}$} & 1497 & & 1497 & \\
\hline & \multicolumn{2}{|c|}{ Alternative 3} & \multicolumn{2}{|c|}{ Alternative 4} \\
\hline & Estimate & t-value & Estimate & t-value \\
\hline $\log \left(w_{\text {male }}\right)$ & $0.613^{* * *}$ & 26.310 & $0.625^{* * *}$ & 26.200 \\
\hline $\log \left(w_{\text {female }}\right)$ & $-0.621^{* * *}$ & 26.820 & $-0.628^{* * *}$ & 26.590 \\
\hline $\log (\#$-children $0 / 2+1)$ & -0.025 & -0.620 & -0.038 & -0.910 \\
\hline $\log (\#$-children $3 / 4+1)$ & -0.023 & -0.560 & -0.039 & -0.900 \\
\hline $\log (\#$-children $5 / 11+1)$ & 0.001 & 0.050 & -0.009 & -0.380 \\
\hline $\log (\#$-children $12 / 16+1)$ & 0.012 & 0.410 & 0.004 & 0.140 \\
\hline $\log (\#$-children $>16+1)$ & -0.006 & -0.110 & -0.011 & -0.200 \\
\hline $\log \left(\right.$ age $\left._{\text {male }}\right)$ & -0.024 & -0.340 & -0.026 & -0.370 \\
\hline $\log \left(\right.$ age $\left._{\text {female }}\right)$ & 0.024 & 0.330 & 0.016 & 0.210 \\
\hline $\log \left(y_{u}+1\right)$ & 0.005 & 0.810 & 0.006 & 0.910 \\
\hline $\mathrm{N}$ & 1497 & & 1497 & \\
\hline
\end{tabular}




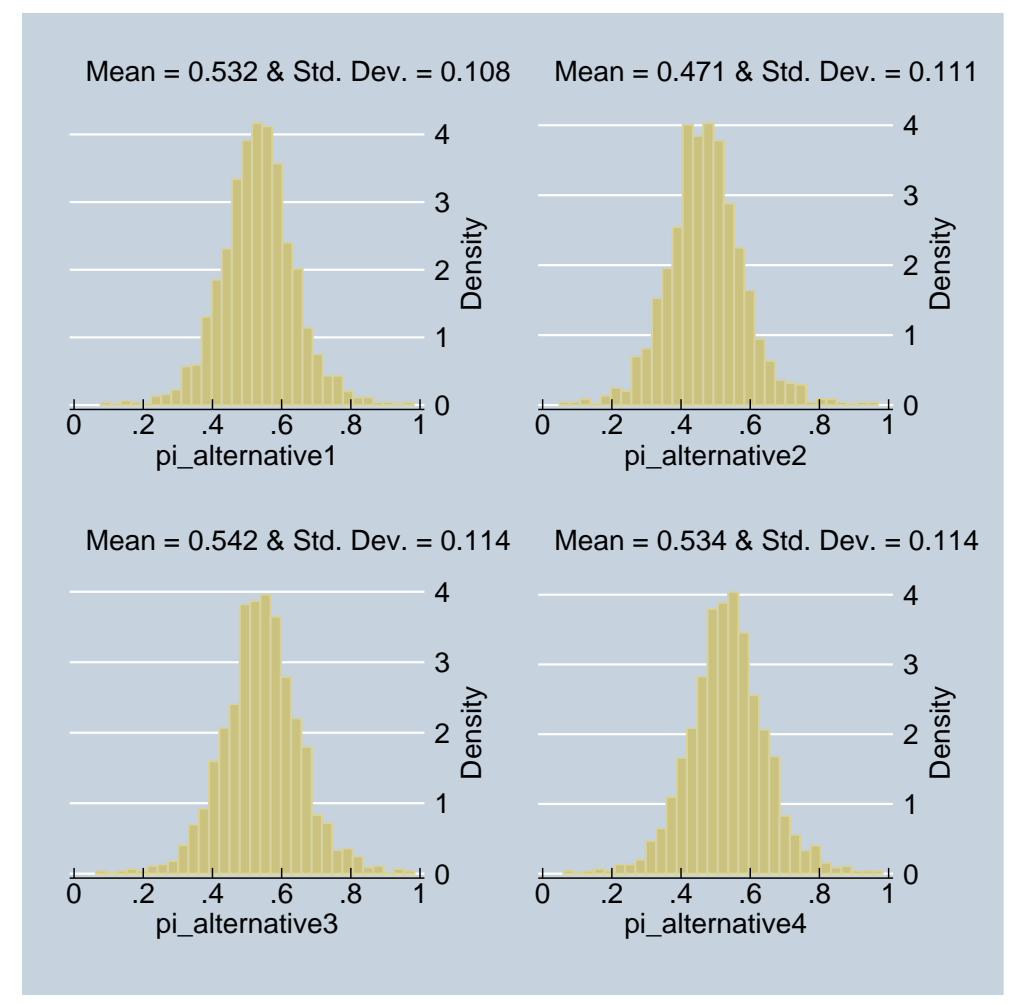

Figure 1: Frequency histograms of $\pi_{n}$ for the different alternatives

Table 5: Variance-correlation matrix of the error vector

\begin{tabular}{lllll}
\hline \hline & $\epsilon_{1}$ & $\epsilon_{2}$ & $\epsilon_{3}$ & $\epsilon_{4}$ \\
$\epsilon_{1}$ & $6.79 \cdot 10^{-7}$ & & & \\
$\epsilon_{2}$ & 0.4106 & $2.30 \cdot 10^{-6}$ & & \\
$\epsilon_{3}$ & 0.7201 & 0.3787 & $5.38 \cdot 10^{-7}$ & \\
$\epsilon_{4}$ & 0.3933 & 0.6488 & 0.2488 & $1.64 \cdot 10^{-6}$ \\
\hline \hline
\end{tabular}


Table 6: Average Wage Elasticities

\begin{tabular}{lrrrr}
\hline \hline & \multicolumn{2}{c}{ Alternative $\mathbf{1}$} & \multicolumn{2}{c}{ Alternative 2 } \\
& $\mathbf{w}_{m}$ & $\mathbf{w}_{f}$ & $\mathbf{w}_{m}$ & $\mathbf{w}_{f}$ \\
$l e_{m}$ & 0.211 & -0.197 & 0.186 & -0.230 \\
$w h_{m}$ & -1.409 & 0.805 & -2.027 & 1.421 \\
$j h_{m}$ & -0.795 & 0.862 & -0.994 & 1.138 \\
$l e_{f}$ & -0.237 & 0.195 & -0.224 & 0.228 \\
$w h_{f}$ & 0.704 & -0.577 & -0.825 & 0.856 \\
$j h_{f}$ & 1.242 & -1.136 & 0.493 & -0.591 \\
& & & & \\
& Alternative 3 & Alternative 4 \\
& $\mathbf{w}_{m}$ & $\mathbf{w}_{f}$ & $\mathbf{w}$ & $\mathbf{w}_{f}$ \\
$w e_{m}$ & 0.134 & -0.144 & 0.261 & -0.291 \\
$w h_{m}$ & -2.151 & 1.757 & -1.830 & 0.584 \\
$j h_{m}$ & -0.283 & 0.353 & -1.019 & 1.238 \\
$l e_{f}$ & -0.260 & 0.241 & -0.073 & 0.118 \\
$w h_{f}$ & 1.256 & -1.272 & 1.021 & -0.587 \\
$j h_{f}$ & 1.266 & -1.042 & -0.429 & -0.048 \\
\hline \hline
\end{tabular}

Table 7: Average Weekly Unearned Income Elasticities

\begin{tabular}{lrrrr}
\hline \hline & Alt. 1 & Alt. 2 & Alt. 3 & Alt. 4 \\
& & & & \\
$l e_{m}$ & 0.035 & 0.034 & 0.019 & 0.028 \\
$w h_{m}$ & 0.105 & 0.138 & -0.061 & 0.061 \\
$j h_{m}$ & -0.108 & -0.110 & -0.037 & -0.091 \\
$l e_{f}$ & 0.000 & 0.010 & 0.022 & 0.005 \\
$w h_{f}$ & -0.004 & -0.014 & 0.123 & 0.013 \\
$j h_{f}$ & 0.008 & -0.038 & -0.155 & -0.023 \\
& & & & \\
$\bar{y}_{u}$ & 40.627 & & & \\
median $_{y_{u}}$ & 17.775 & & & \\
$\sigma_{y_{u}}$ & 73.420 & & & \\
\hline \hline
\end{tabular}


Table 8: Child Effects

Alternative 1

$\begin{array}{lrrrrr} & \mathbf{c 0 2} & \mathbf{c 3 4} & \mathbf{c 5 1 1} & \mathbf{c 1 2 1 5} & \mathbf{c 1 6 1 8} \\ l e_{m} & -0.0042 & -0.0051 & -0.0106 & -0.0018 & -0.0024 \\ w h_{m} & 0.1002 & -0.0050 & -0.0122 & 0.0287 & -0.0124 \\ j h_{m} & -0.0309 & 0.0134 & 0.0280 & -0.0026 & 0.0078 \\ l e_{f} & 0.0040 & 0.0056 & 0.0101 & 0.0030 & 0.0028 \\ w h_{f} & -0.1085 & 0.0133 & 0.0109 & -0.0034 & 0.0073 \\ j h_{f} & 0.0030 & -0.0129 & -0.0143 & 0.0140 & -0.0124\end{array}$

Alternative 2

$\begin{array}{lrrrrr} & \mathbf{c 0 2} & \mathbf{c 3 4} & \mathbf{c 5 1 1} & \mathbf{c 1 2 1 5} & \mathbf{c 1 6 1 8} \\ l e_{m} & -0.0076 & -0.0037 & -0.0066 & 0.0009 & 0.0000 \\ w h_{m} & -0.0363 & 0.0137 & 0.0140 & -0.0070 & -0.0008 \\ j h_{m} & 0.0244 & 0.0005 & 0.0060 & 0.0020 & 0.0002 \\ l e_{f} & 0.0049 & 0.0023 & 0.0023 & -0.0008 & 0.0000 \\ w h_{f} & 0.0191 & -0.0159 & -0.0608 & 0.0188 & 0.0010 \\ j h_{f} & -0.0321 & 0.0025 & -0.0050 & 0.0011 & 0.0000\end{array}$

Alternative 3

$\begin{array}{lrrrrr} & \mathbf{c 0 2} & \mathbf{c 3 4} & \mathbf{c 5 1 1} & \mathbf{c 1 2 1 5} & \mathbf{c 1 6 1 8} \\ l e_{m} & -0.0083 & -0.0012 & 0.0003 & 0.0013 & -0.0004 \\ w h_{m} & -0.1142 & -0.0027 & 0.0005 & -0.0155 & -0.0040 \\ j h_{m} & 0.0445 & 0.0035 & -0.0009 & 0.0011 & 0.0018 \\ l e_{f} & 0.0098 & 0.0012 & -0.0003 & -0.0017 & 0.0005 \\ w h_{f} & 0.0835 & 0.0033 & -0.0002 & 0.0128 & 0.0019 \\ j h_{f} & -0.0745 & -0.0017 & 0.0012 & 0.0002 & -0.0026\end{array}$

Alternative 4

\begin{tabular}{lrrrrr} 
& $\mathbf{c 0 2}$ & $\mathbf{c 3 4}$ & $\mathbf{c 5 1 1}$ & $\mathbf{c 1 2 1 5}$ & $\mathbf{c 1 6 1 8}$ \\
$l e_{m}$ & -0.0204 & -0.0043 & -0.0086 & 0.0041 & 0.0008 \\
$w h_{m}$ & -0.0713 & -0.0328 & -0.0319 & 0.0329 & -0.0027 \\
$j h_{m}$ & 0.0609 & 0.0180 & 0.0260 & -0.0142 & -0.0094 \\
$l e_{f}$ & 0.0346 & 0.0052 & 0.0192 & -0.0094 & 0.0032 \\
$w h_{f}$ & 0.0504 & 0.0262 & 0.0182 & -0.0164 & -0.0009 \\
$j h_{f}$ & -0.2644 & -0.0287 & -0.1299 & 0.0700 & -0.0279 \\
\hline \hline
\end{tabular}

